\title{
Blood protein adsorption and compatibility studies of gold nanoparticles
}

\author{
N. Nimi • Willi Paul $\cdot$ Chandra P. Sharma
}

Published online: 22 February 2011

(C) The Author(s) 2011. This article is published with open access at Springerlink.com

\begin{abstract}
Gold nanoparticles are considered to be real jewels. The significant growth of their application for labeling, delivery, heating, and sensing shows their significance in biology and/or life sciences. PEGylated gold nanoparticles also have significant application in drug and gene delivery. However, comprehensive information on the compatibility of these nanoparticles to blood is limited in literature. An attempt has been made to study the protein adsorption, blood cell aggregation, and $\mathrm{C} 3$ adsorption onto these particles to evaluate its complement activation potential and blood compatibility. It has been observed that these nanoparticles do not induce any complement activation or blood cell aggregation. Particles were non-hemolytic and the adsorptions of proteins were negligible which further validates its significance in drug delivery and gene delivery applications.
\end{abstract}

Keywords Gold nanoparticles · PEGylated gold nanoparticles $\cdot$ Blood compatibility Protein adsorption

\section{Introduction}

In recent years, there has been a significant increase in nanoparticle research due to their beneficial applications in the fields of biomedical, bioanalytical, and biosensing. Metallic nanoparticles including gold nanoparticles (GNP) show optical plasmon resonance, which makes them suitable for applications in the biological fields like

\footnotetext{
N. Nimi $\cdot$ W. Paul $\cdot$ C. P. Sharma $(\bowtie)$

Division of Biosurface Technology,

Biomedical Technology Wing,

Sree Chitra Tirunal Institute for Medical Sciences and Technology,

Poojappura, Thiruvananthapuram 695012, India

e-mail: sharmacp@sctimst.ac.in
}

chemical and biological sensing, surface enhanced spectroscopy, bio tagging, and drug delivery [1]. In recent times biosensors have attracted much attention due to their applicability in clinical diagnostics, pharmaceuticals, and in the food industry $[2,3]$. GNPs have a wide range of applications as they exhibit a high surface plasmon resonance in aqueous media. Since the light-scattering signal is intense and much brighter than chemical fluorophores, it is mainly applied in single-molecule imaging, where the use of dyes, fluorophores, or quantum dots is limited by low signal intensities [4]. The GNPs find significant applications also in drug delivery as they are capable of encapsulating active drugs and targeting [5]. Colloidal GNPs represent a completely novel technology in the field of particle-based tumor-targeted drug delivery. GNPs are found to be more stable when they are covalently coupled with thiol entities. The presence of the thiol groups on the surface reduces the formation of aggregates $[6,7]$. The monolayer of polyethylene glycol (PEG) over GNP has been found to improve the cellular internalization properties [8]. Surface modification of gold nanoparticulate carriers with PEG [9] has emerged as a strategy to enhance solubility of hydrophobic drugs, prolong circulation time, minimize non-specific uptake, and allow for specific tumor targeting through the enhanced permeability and retention effect. PEG modification on thiolated GNPs can be used as drug and gene carriers with specific tumor targeting properties through a flexible tether, promoting tumortargeting capabilities, thereby enhancing efficacy of anticancer therapeutic strategies [10]. Nanoparticles of gold are attracting increased attention in nanotechnology, but there are applications in medicine that are still relatively unexplored [11, 12]. However, ionic forms of gold have been shown to have cytotoxicity on various cell types and adverse effects on red blood cells (RBC) [13]. Earlier 
reviews suggest that GNPs bind to thiol groups and, applying a coating on the surface, reduce aggregation and give stability to the nanoparticles [14]. PEGylation helps to reduce the toxicity and improve blood compatibility [15]. Hence, an attempt has been made to study the blood compatibility of the gold and PEGylated gold nanoparticles (pGNP). The blood compatibility studies that have been done are hemolysis, aggregation studies of blood cells, protein adsorption and complement $\mathrm{C} 3$ adsorption studies, etc.

\section{Materials and methods}

Gold (III) chloride hydrate $\left(\mathrm{HAuCl}_{4}\right)$ was purchased from Spectrochem India Pvt. Ltd. 11-Mercaptoundecanoic acid, $O$-(2-aminoethyl) $O^{\prime}$-methyl polyethylene glycol (MW 20,000) (amino-PEG) and 1-ethyl-3-(3-dimethylaminopropyl) carbodiimide (EDC) were obtained from Sigma Chemical Co. USA. Complement protein $\mathrm{C} 3$ kit was purchased from Orion Diagnostica, Finland. All other chemicals and other reagents used were of analytical reagent grade.

Preparation of gold nanoparticles

The GNPs were prepared by the standard procedure of reduction with citrate [16]. Briefly, $20 \mathrm{ml}$ of $1 \mathrm{mM}$ solution of gold chloride $\left(\mathrm{HAuCl}_{4}\right)$ was allowed to boil and $2 \mathrm{ml}$ of $1 \%$ trisodium citrate solution was added dropwise. The heating was continued for half an hour until a deep wine red color appeared.

Preparation of PEGylated gold nanoparticles

To $40 \mathrm{ml}$ of $10 \mathrm{mM} \mathrm{HAuCl}_{4}$ solution in methanol, $10 \mathrm{mM}$ 11-mercaptoundecanoic acid in methanol $(10 \mathrm{ml})$ was added and stirred well. Twenty-five milliliters of $0.3 \mathrm{M}$ aqueous solution of sodium borohydride $\left(\mathrm{NaBH}_{4}\right)$ was added dropwise with vigorous stirring for $1 \mathrm{~h}$. The nanoparticles obtained were centrifuged and washed with methanol to remove the excess thiol present in the reaction mixture. In $50 \mathrm{mg}$ of these thiolated gold nanoparticles, $0.04 \mathrm{M}$ EDC in $5 \mathrm{ml}$ of phosphate buffer ( $\mathrm{pH}$ 6.8) was added and stirred well for $2 \mathrm{~h}$. One hundred milligrams of amino-PEG was added and stirred overnight. It was then filtered through a centrifugal filter $(30 \mathrm{kD})$, washed in 6.8 $\mathrm{pH}$ buffer and finally freeze-dried.

Particle size and zeta potential determination by photon correlation spectroscopy and laser Doppler anemometry

The particle size and the zeta potential of the gold nanoparticles (GNP) and pGNP were analyzed by photon correlation spectroscopy and laser Doppler anemometry,

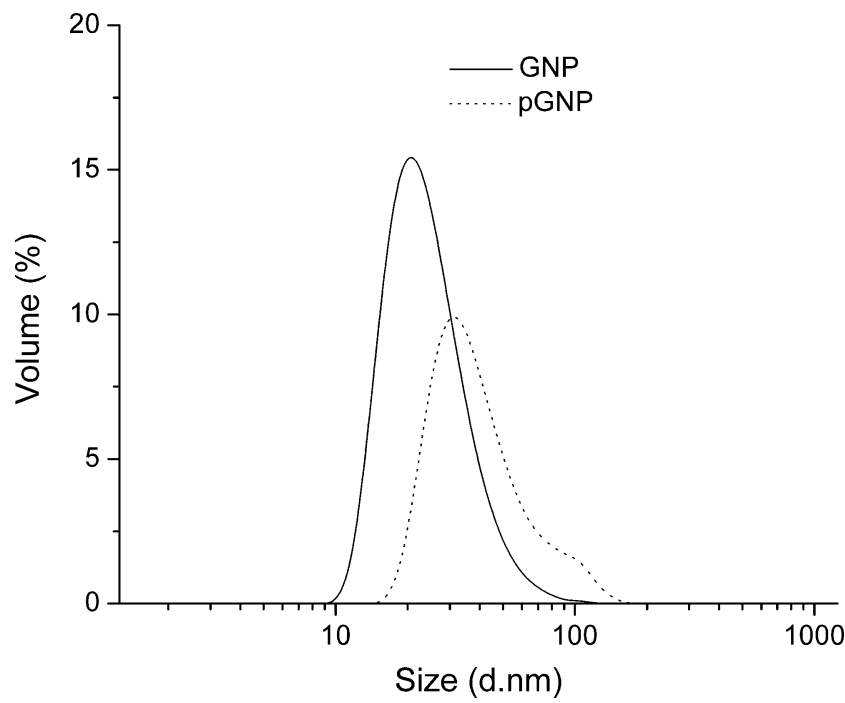

Fig. 1 Particle size distributions of GNPs and pGNPs obtained via photon correlation spectroscopy

respectively, with a Zetasizer, Nano ZS (Malvern Instruments Limited, UK) at $25^{\circ} \mathrm{C}$.

\section{UV-visible spectroscopy}

The visible absorption spectra of GNP and pGNP suspensions were obtained by UV-Vis spectrophotometer (Varian).

Blood compatibility studies

Blood cell aggregation and hemolysis studies RBCs were separated by centrifuging fresh blood at $700 \mathrm{rpm}$. This was

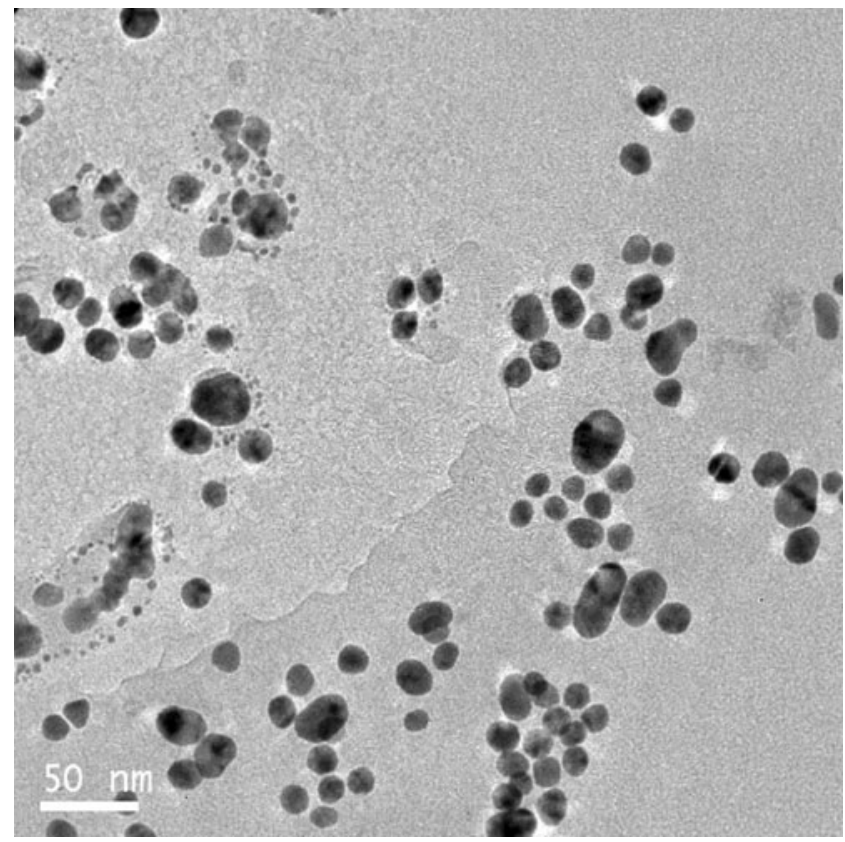

Fig. 2 Transmission electron micrograph of GNPs 


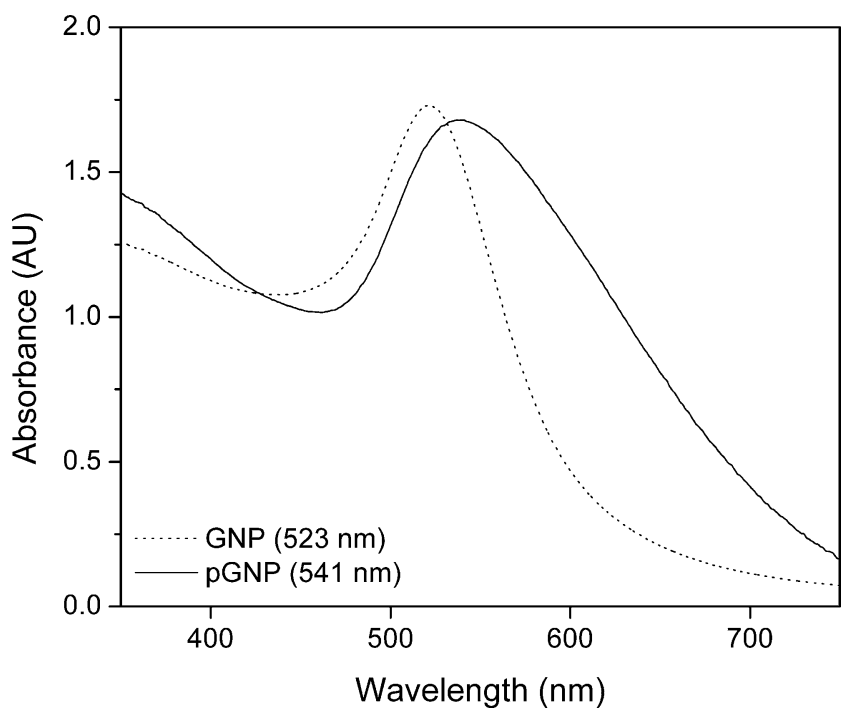

Fig. 3 Visible absorption spectra of GNPs and pGNPs

washed with saline and diluted in saline in a ratio of 1:4. White blood cells (WBC) were isolated by centrifuging the fresh blood after layering with histopaque for $20 \mathrm{~min}$ at $700 \mathrm{rpm}$. Platelet rich plasma (PRP) was collected by centrifuging the fresh blood at $1,000 \mathrm{rpm}$ for $20 \mathrm{~min}$ layered on histopaque solution. In $1 \mathrm{mg}$ each of gold and pGNP, $100 \mu$ of the diluted RBC, WBC suspension, or PRP were added and incubated for $30 \mathrm{~min}$ at $37^{\circ} \mathrm{C}$. Polyethyleneimine (PEI) and saline were taken as positive and negative controls, respectively for all studies. Aggregations, if any, were observed through a phase contrast microscope (Leica DM IRB, Germany) at a magnification of $\times 40$. Hemolysis assay was done on the nanoparticles as reported elsewhere [16]. Normal saline was used as negative control $(0 \%$ lysis) and distilled water as positive control (100\% lysis). The absorbance was measured at $541 \mathrm{~nm}$ by UV-Vis spectrophotometer (Varian).

Protein adsorption studies The plasma was separated by centrifugation of fresh blood at $700 \mathrm{rpm}$. Ten milligrams each of the nanoparticles were dispersed in $200 \mu$ l of saline. To this, $200 \mu \mathrm{l}$ of plasma was added and incubated for $1 \mathrm{~h}$. After incubation, the plasma was separated by centrifugation at 10,000 rpm and diluted with saline. The proteins in the plasma samples before and after incubation were separated by polyacrylamide gel electrophoresis (PAGE) using discontinuous native PAGE method of Laemmli [17]. A resolving gel of $12 \%$ and a stacking gel $4 \%$ were used. Electrophoresis was carried out at $100 \mathrm{~V}$ for $90 \mathrm{~min}$ using
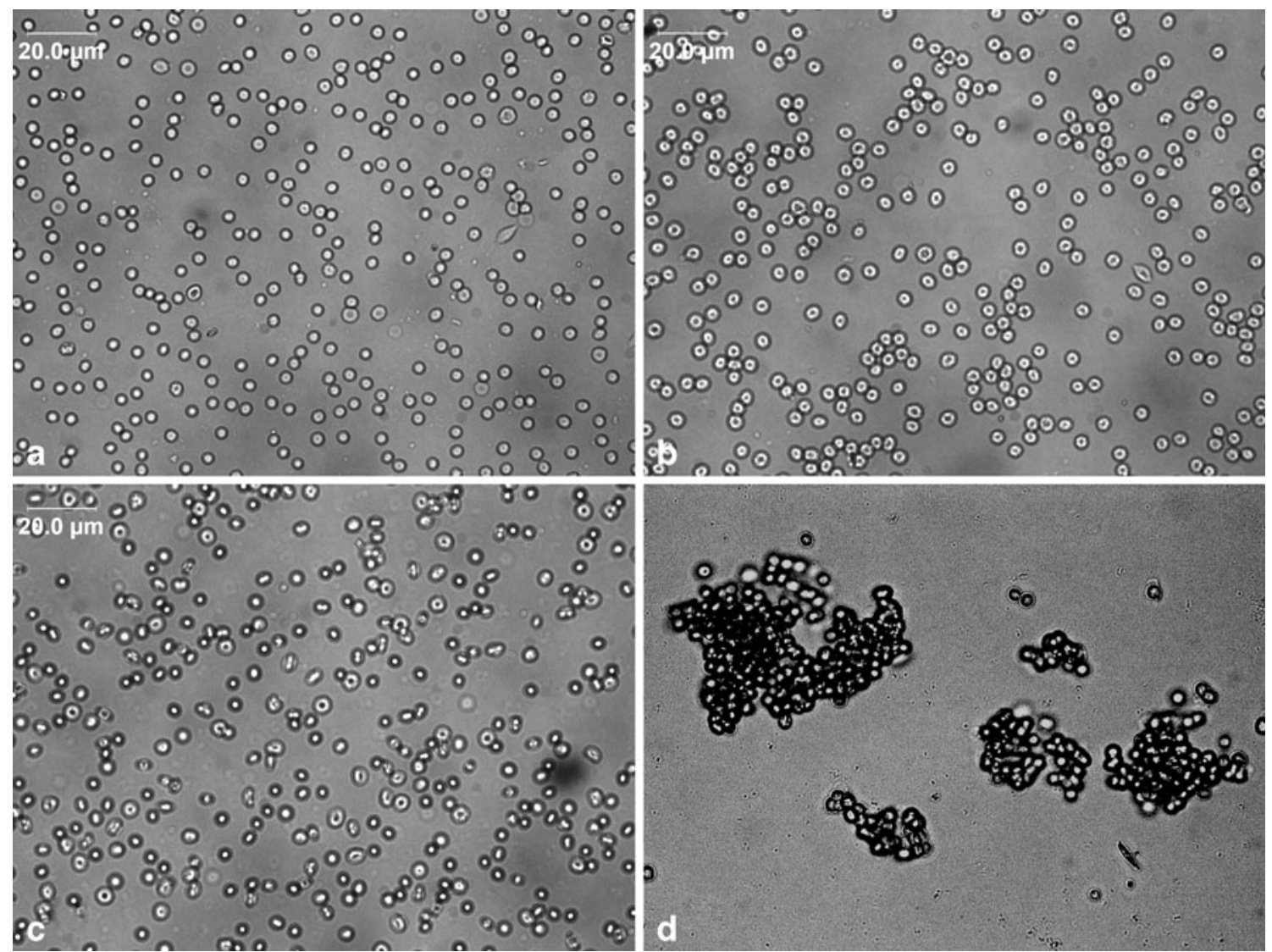

Fig. 4 Aggregation of RBCs by incubation of a GNPs, $\mathbf{b}$ pGNPs, $\mathbf{c}$ normal saline (negative control), and $\mathbf{d}$ polyethyleneimine (positive control) 
Mini-PROTEAN II electrophoresis cell (Bio-Rad, CA, USA). The gel was digitalized using an image analyzer (LAS 4000, Fuji) and the densitometry scans were done with the software Multi Gauge V3.

Complement activation The complement activation of the nanoparticles was determined by turbidimetric method assessing the depletion of complement protein $\mathrm{C} 3$ on incubation with the nanoparticles. The particle suspensions $(100 \mu \mathrm{l})$ were incubated for $1 \mathrm{~h}$ at $37^{\circ} \mathrm{C}$ with $100 \mu \mathrm{l}$ of citrated blood. The final concentration of the nanoparticles in the assay system was maintained at $10 \mu \mathrm{g} / \mathrm{ml}$ of blood. The assay was done as per the protocol provided by the kit manufacturer.

\section{Results and discussion}

The gold nanoparticles were prepared by the standard procedure of reducing of $\mathrm{Au}^{3+}$ ions to gold in the presence of citrate. The citrate has also acted as a stabilizing agent, by forming a layer of citrate ions on the GNP preventing the aggregation of the nanoparticles. For the preparation of pGNP initially the gold chloride was modified with 11- mercaptoundecanoic acid to form thiolated GNP. Thiolated GNPs were further modified with amino-PEG after activating the carboxyl groups with water-soluble EDC. The particle size distributions of the nanoparticles are shown in Fig. 1. GNPs and pGNPs had mean diameters of 21.04 and $32.67 \mathrm{~nm}$, respectively. A representative transmission electron micrograph of GNP is given in Fig. 2. The zeta potentials of nanoparticles at neutral $\mathrm{pH}(\mathrm{pH} 7)$ were found to be -47 and $-22 \mathrm{mV}$, respectively for GNPs and pGNPs. The increase in the zeta potential is an indication of PEGylation of the GNPs. Formation of PEG monolayer over GNPs has been reported to improve the cellular internalization properties [18].

The visible absorption spectrum obtained from UVvisible spectrophotometer showed a red shift in the wavelength for the pGNPs as demonstrated in Fig. 3. The GNPs showed an absorption peak at around $523 \mathrm{~nm}$, and for the pGNP particles, a peak at $541 \mathrm{~nm}$ was observed. This is consistent with the obtained particle size distributions and again confirmed the PEGylation of GNPs. For larger nanoparticles $(d>25 \mathrm{~nm})$, the extinction cross section is dependent on higher-order multipole modes within the full Mie equation and the extinction spectrum is then also dominated by quadrupole and octopole absorption as well as scattering. These higher oscillation modes explicitly

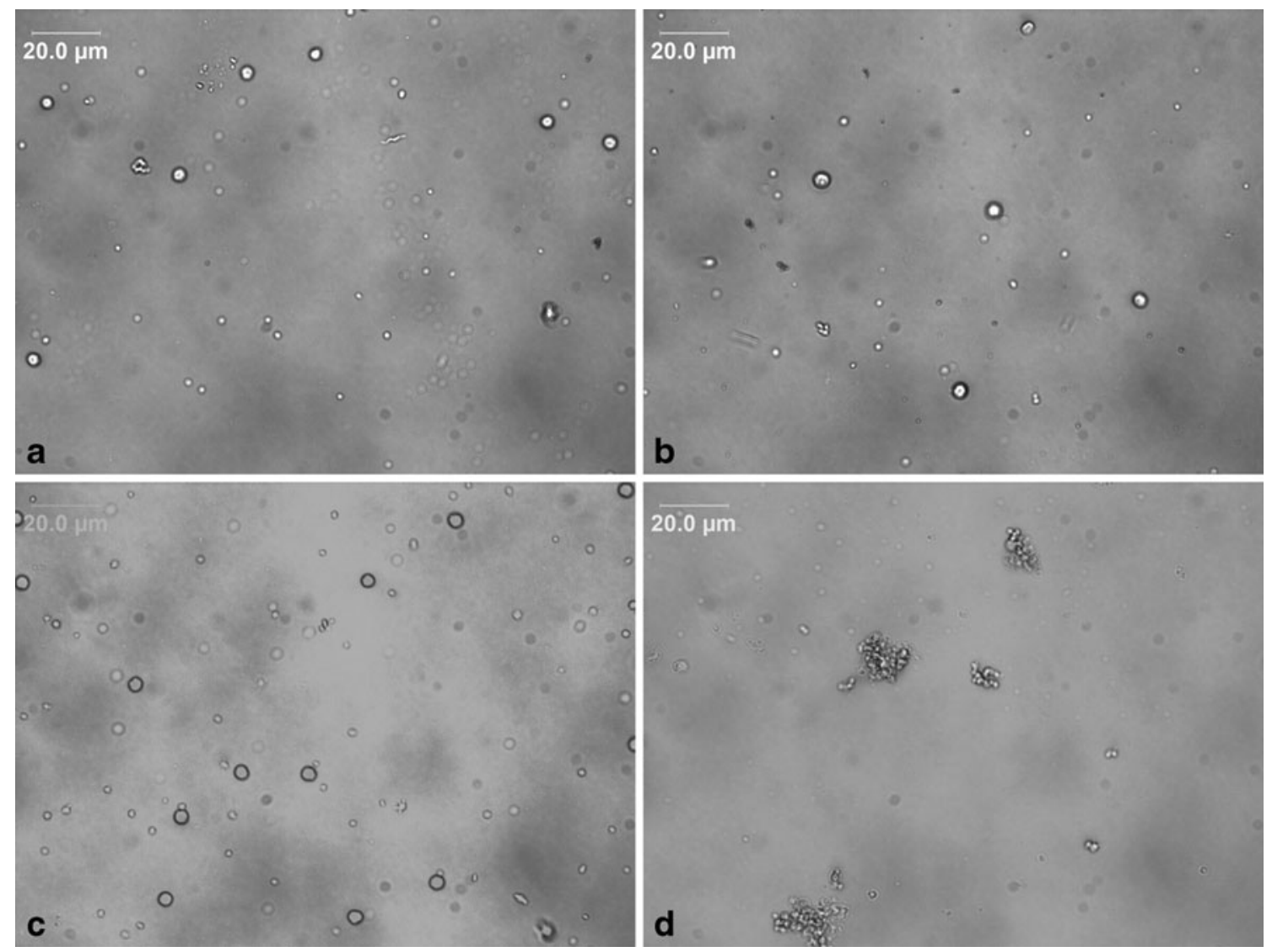

Fig. 5 Aggregation of WBC by incubation of a GNPs, $\mathbf{b}$ pGNPs, $\mathbf{c}$ normal saline (negative control), and d polyethyleneimine (positive control) 

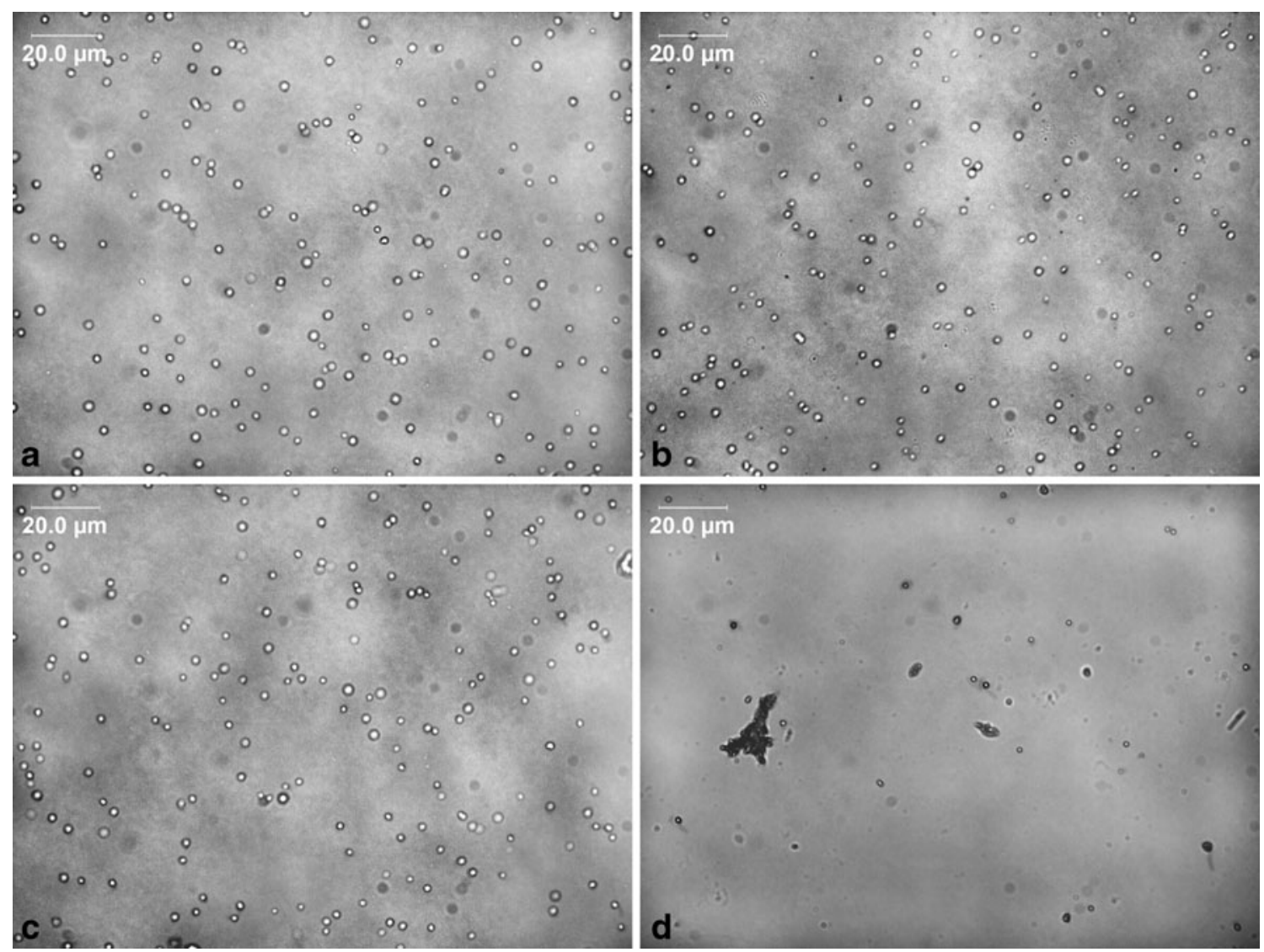

Fig. 6 Aggregation of platelets by incubation of a GNPs, $\mathbf{b}$ pGNPs, $\mathbf{c}$ normal saline (negative control), and $\mathbf{d}$ polyethyleneimine (positive control)

depend on the particle size and with increasing size the plasmon absorption maximum is shifted to longer wavelength and the bandwidth increases [19-21].

The aggregations of the blood cells on interaction with the nanoparticles are shown in Figs. 4, 5 and 6, respectively for RBCs, WBCs, and platelets. It revealed no aggregation of blood cells on incubation of nanoparticles at a higher interaction ratio of $10 \mathrm{mg} / \mathrm{ml}$. PEI, which was used as positive control, showed aggregation whereas saline used as negative control did not show any aggregation. The same was visible with the hemolytic property of the nanoparticles. The hemolysis induced by GNPs was $0.1 \%$ and that for pGNPs was $0.15 \%$ which was well within the acceptable limits of $1 \%$ [22].

Measuring $\mathrm{C} 3 \mathrm{a}$ or $\mathrm{C} 5 \mathrm{a}$ in blood or serum after contact with a material has been the most usual way of assessing complement activation. It has been claimed that a surface is biocompatible if these markers are not increased in the fluid phase [23]. Since $\mathrm{C} 3$ is cleaved to $\mathrm{C} 3 \mathrm{a}$ and $\mathrm{C} 3 \mathrm{~b}$ by the contact of the surface with blood, irrespective of whether the activation occurs via classical or alternative pathways, and also $\mathrm{C} 3 \mathrm{a}$ could be adsorbed on to the material surface just like any other proteins, $\mathrm{C} 3$ depletion in the medium can be taken as an indirect measure of complement activation.
The amount of $\mathrm{C} 3$ in blood (pre-incubation) was $127 \mathrm{mg} \%$. After incubation with GNPs and pGNPs, it was $124 \mathrm{mg} \%$ and $129 \mathrm{mg} \%$, respectively. On incubation of nanoparticles with blood, no depletion of $\mathrm{C} 3$ protein was observed,

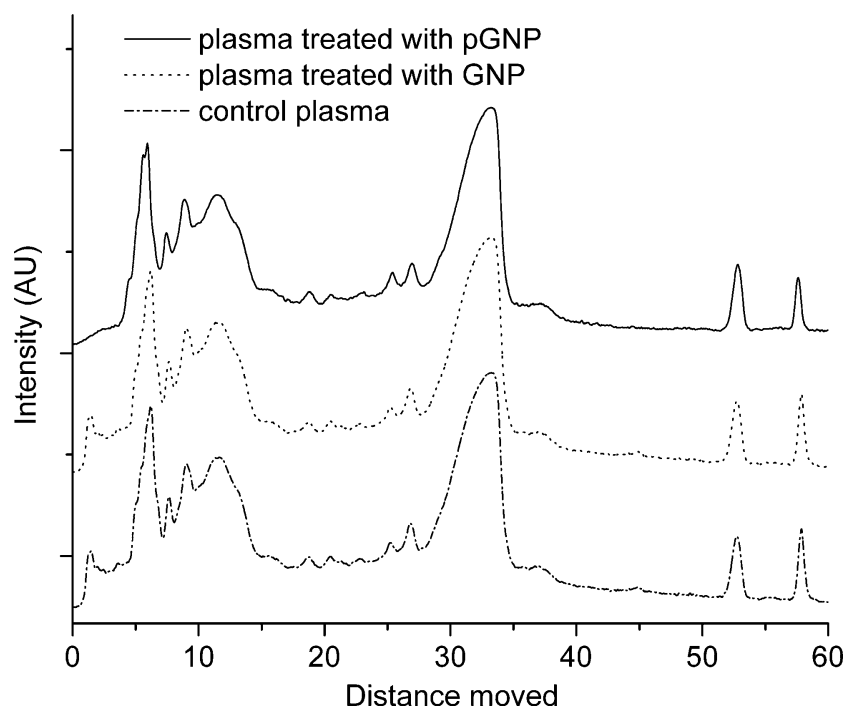

Fig. 7 Densitometry scan of native PAGE of plasma proteins before and after incubation with GNPs and pGNPs 
which indicates that GNPs as well as pGNPs are not complement activating.

The initial event when a material comes in contact with blood is the adsorption of proteins. The nature of protein and amount of protein adsorbed will directly influence the compatibility of the nanoparticles with the blood. The adsorption studies evaluated using native PAGE electrophoresis demonstrated no significant adsorption of proteins occurring onto GNPs as well as pGNPs as shown in the densitometry scan of the treated plasma (Fig. 7). There was a correlation of the adsorption of the globular proteins with the blood cell aggregation showing no activation or aggregation of cells on incubation with gold nanoparticles.

The results obtained from the blood compatibility evaluation of gold and PEGylated gold support its usage as vectors for the applications in drug delivery, gene delivery, or as biosensors, where a direct contact with blood occurs.

Acknowledgment We are grateful to the director and the head of BMT Wing of SCTIMST for providing facilities for the completion of this work. This work was supported by the Department of Science and Technology, Government of India through the project "Facility for nano/ microparticle based biomaterials - advanced drug delivery systems" \#8013, under the Drugs and Pharmaceuticals Research Program.

Open Access This article is distributed under the terms of the Creative Commons Attribution License which permits any use, distribution, and reproduction in any medium, provided the original author(s) and source are credited.

\section{References}

1. Sperling RA, Rivera Gil P, Zhang F, Zanella M, Parak WJ (2008) Chem Soc Rev 37:1896-1908

2. Gerard M, Chaubey A, Singh R (2002) Biosens Bioelectron 17:345
3. Pandey P, Singh PS, Arya KS, Gupta V, Dutta M, Singh S, Malhotra BD (2007) Langmuir 23:3333-3337

4. Yguerabide J, Yguerabide EE (1998) Anal Biochem 262:137156

5. Ghosh P, Han G, De M, Kim CK, Rotello VM (2008) Adv Drug Deliv Rev 60:1307-1315

6. Paciotti GF, Myer L, Weinreich D, Goia D, Pavel N, McLaughlin RE, Tamarkin L (2004) Drug Deliv 11:169-183

7. Shi W, Sahoo Y, Swihart MT (2004) Colloids Surf A Physicochem Eng Asp 246:109-113

8. Liu Y, Shipton MK, Ryan J, Kaufman ED, Franzen S, Feldheim DL (2007) Anal Chem 79:2221-2229

9. Durgadas CV, Kaladhar K, Divya P, Sreenivasan K, Sharma CP (2009) Trends Biomater Artif Organs 23:86-92

10. Alcantar NA, Avdil ES, Israelachvili TN (2000) J Biomed Mater Res 51:343-351

11. Pissuwan D, Valenzuela SM, Cortie MB (2006) Trends Biotechnol 24:62-67

12. Paciotti GF, Kingston DGI, Tamarkin L (2006) Drug Dev Res 67:47-54

13. Garner M, Rglinski J, Smith WE, Stewart MJ (1994) J Inorg Biochem 56:283-290

14. Johnson SR, Evans SD, Brydson R (1998) Langmuir 14:66396647

15. Lee JH, Lee HB, Andrade JD (1995) Prog Polym Sci 20:10431079

16. Murthy N, Robichaud JR, Tirrell DA, Stayton PS, Hoffman AS (1999) J Control Release 61:137-143

17. Laemmli UK (1970) Nature 227:680-685

18. Liu Y, Shipton MK, Ryan J, Kaufman ED, Franzen S, Feldheim DL (2007) Anal Chem 79:2221-2229

19. Kerker M (1969) Light and other electromagnetic radiation. Academic, New York

20. Bohren CF, Huffman DR (1983) Absorption and scattering of light by small particles. Wiley, New York

21. Creighton JA, Eadon DG (1991) J Chem Soc Faraday Trans 87:3881-3891

22. ASTM Standard F756-08 (2008) Standard practice for assessment of hemolytic properties of materials. ASTM International, West Conshohocken. doi:10.1520/F0756-08

23. Mollnes TE, Riesenfeld J, Garred P (1995) Artif Organs 19:909-917 